\title{
Longitudinal variation of equatorial electrojet and the occurrence of its counter electrojet
}

\author{
A. Babatunde Rabiu ${ }^{1}$, Olanike Olufunmilayo Folarin ${ }^{1,2}$, Teiji Uozumi ${ }^{3}$, Nurul Shazana Abdul Hamid ${ }^{4}$, and \\ Akimasa Yoshikawa ${ }^{3}$ \\ ${ }^{1}$ Centre for Atmospheric Research, National Space Research and Development Agency, Anyigba, Nigeria \\ ${ }^{2}$ Ionospheric and Space Physics Laboratory, Department of Physics, University of Lagos, Akoka, Lagos State, Nigeria \\ ${ }^{3}$ International Center for Space Weather Science and Education ICSWSE, Kyushu University, 744, Motooka, Nishi-ku, \\ Fukuoka, 819-0395, Japan \\ ${ }^{4}$ National University of Malaysia, Faculty of Science \& Technology, Selangor, Malaysia \\ Correspondence to: A. Babatunde Rabiu (tunderabiu2@gmail.com)
}

Received: 1 August 2016 - Revised: 28 February 2017 - Accepted: 7 March 2017 - Published: 7 April 2017

\begin{abstract}
We examined the longitudinal variability of the equatorial electrojet (EEJ) and the occurrence of its counter electrojet (CEJ) using the available records of the horizontal component $H$ of the geomagnetic field simultaneously recorded in the year 2009 (mean annual sunspot number $R_{z}=3.1$ ) along the magnetic equator in the South American, African, and Philippine sectors. Our results indicate that the EEJ undergoes variability from one longitudinal representative station to another, with the strongest EEJ of about $192.5 \mathrm{nT}$ at the South American axis at Huancayo and a minimum peak of $40.7 \mathrm{nT}$ at Ilorin in western Africa. Obtained longitudinal inequality in the EEJ was explicable in terms of the effects of local winds, dynamics of migratory tides, propagating diurnal tide, and meridional winds. The African stations of Ilorin and Addis Ababa registered the greatest \% of CEJ occurrence. Huancayo in South America, with the strongest electrojet strength, was found to have the least occurrence of the CEJ. It is suggested that activities that support strong EEJ inhibits the occurrence of the CEJ. Percentage of occurrence of the CEJ varied with seasons across the longitudes. The order of seasonal variation of morning occurrence does not tally with the evening occurrence order at any station. A semiannual equinoctial maximum in percentage of morning occurrence of the CEJ was obtained at Huancayo and Addis Ababa. Only Addis Ababa recorded equal equinoctial maxima in percentage of evening occurrence of the CEJ. The seasonal distribution of the occurrences of the CEJ at different time regimes implies a seasonal variability
\end{abstract}

of causative mechanisms responsible for the occurrence of the CEJ.

Keywords. Atmospheric composition and structure (instruments and techniques)

\section{Introduction}

Space-based technology and applications have become an essential tool in many countries, especially developing ones, making the world a "global village". Earth satellite communication and other applications of satellite technology have made the study of space environment, including the ionosphere, more popular in recent times. As a result, the study of the equatorial ionosphere and its current systems has continued to gain much interest due to the complexities associated with the region (Rabiu et al., 2007).

The equatorial ionosphere over the dip equator is characterized by a number of distinctive electrodynamic processes, which include an eastward current named the equatorial electrojet (EEJ) (Chapman, 1951). The EEJ is considered as a band of non-uniform intense eastward ionospheric current flowing within a latitudinal extent of $\pm 3^{\circ}$ on either side of the dip equator at a lower altitude E region centred at around $106 \pm 2$ km (Richmond, 1973; Fambitakoye and Mayaud, 1976a, b; Forbes, 1981; Reddy, 1981; Stening, 1985; Onwumechili, 1997; Rabiu et al., 2013). This is associated with the fact that the magnetic lines of force around the dip equator are horizontal; thus, a large vertical, electrical polariza- 
tion field, which is primarily responsible for the enhanced eastward currents, can be set up (Onwumechili, 1997).

On occasion during quiet periods, at certain hours of the day particularly in the early morning and evening, the daytime EEJ strength is weakened and reverses direction for a short period, after which it later returns to its normal afternoon value before it disappears around sunset (Gouin, 1962; Gouin and Mayaud, 1967). The counter electrojet (CEJ) is the EEJ reversal during magnetically quiet periods (Gouin and Mayaud, 1967). This event was first observed during the study of the magnetic records at Addis Ababa, Ethiopia, in 1962 by Gouin (1962). It manifests in the magnetograms as a depression in plot of $H$ versus time. Hanuise et al. (1983) showed a consistent electrical connection between the CEJ and the $S_{q}$ current system, with two horizontal current vortices of opposite directions that flow on each side of the noon sector, anticlockwise in the morning and clockwise in the afternoon. These current vortices produce a poleward current flow at low latitudes at noon (Gurubaran, 2002).

Since the discovery of the EEJ at Huancayo (Peru) as well as the CEJ at Addis Ababa (Ethiopia) near the dip equator, studies across various longitudinal sectors have shown that both phenomena display significant diurnal, seasonal, dayto-day, and solar cycle and longitudinal variabilities (Richmond, 1973; Kane, 1976; Mayaud, 1977; Forbes, 1981; Reddy, 1981, 1989; Stening, 1995; Rastogi, 1989; AmoryMazaudier et al., 1993; Mazaudier et al., 2005; Doumouya et al., 1998; Doumouya and Cohen, 2004; Luhr et al., 2004; Rabiu et al., 2011; Yizengaw et al., 2014).

The strength of the EEJ and its width have been established to change with longitude (Onwumechili, 1997; Rastogi, 1962). Jadhav et al. (2002) studied the EEJ strength along the Indian and American sectors and showed that the EEJ strength varies with longitude. Rabiu et al. (2011) clearly revealed that along the African sector, the EEJ at the western sector appears weaker than the EEJ at the eastern sector. This west-east asymmetrical behaviour in EEJ strength in the African sector is further confirmed by Yizengaw et al. (2014) using data from an array of different magnetometers. In addition, Yizengaw et al. (2014) reported higher values of EEJ and $\boldsymbol{E} \times \boldsymbol{B}$ drift distribution in the western American sector and decrement towards the eastern longitudes all the way to the eastern African sector.

Chandrasekhar et al. (2014) noticed that a few studies have reported that there is large day-to-day variability of the CEJ phenomena over a $45^{\circ}$ longitude separation, which sometimes occurs over a large longitudinal difference (Onwumechili and Akasofu, 1972; Mayaud, 1977). Kane and Trivedi (1980) demonstrated the characteristics of CEJ events at two locations in the Brazilian region across the east and west coasts of the South American sector, separated by less than $30^{\circ}$ longitude. Patil et al. (1990a, b) reported more CEJ occurrence during low solar activity periods than high solar activity periods in the Indian and American sectors. Rangarajan and Rastogi (1993) investigated the after- noon CEJ events at equatorial stations Addis Ababa and Kodaikanal and concluded that the afternoon CEJ is localized in longitude, and on some occasions, the events may not occur on the same day, even at locations separated by a narrow longitude of $2 \mathrm{~h}$.

Onwumechili (1997) concluded that the properties of $S(2,2), S(2,4)$ tidal modes suggest that they can contribute to the cause of the CEJ. However, the contributions of vertical winds and local east-west neutral winds with vertical shear are more obvious, whether or not they are of tidal origins. He stated that the very high occurrence frequency of the CEJ near dawn and near dusk appears to be partly due to late morning reversal and early evening reversal of the vertical electric field.

Doumouya et al. (1998) reported CEJ occurrences along the western African longitudes and observed that morning as well as afternoon occurrences of the CEJ show seasonal variability. Alex and Mukherjee (2001) compared CEJ events along two equatorial stations, Trivandrum and Addis Ababa, which are $40^{\circ}$ apart in longitude, and showed that there are some differences in CEJ events when observed in different longitudinal sectors. Bolaji et al. (2014) reported more frequent occurrence of morning CEJ events at Ilorin in 2009 and attributed this to the late reversal of westward to eastward currents. Rabiu et al. (2017) investigated the simultaneity and asymmetry in the occurrence of the CEJ along African longitudes and most frequently found (about $77 \%$ ) simultaneous occurrence of CEJ in the morning at two equatorial stations, one in the west of the continent and the other in the east.

Stening et al. (1996) suggested an association of sudden stratospheric warming (SSW) with the occurrence of CEJ events during their study of the occurrence of the CEJ during the winter months. A distinctive pattern in the equatorial daytime $\boldsymbol{E} \times \boldsymbol{B}$ drift during the SSW years was also reported by Chau et al. (2009). Balan et al. (2012) also showed that the low-latitude thermosphere and ionosphere record very clear effects of the SSW taking place in the polar stratosphere during an unusual solar minimum. The clear effects at the unusual minimum are interpreted in terms of the $8 \mathrm{~h}$ tide during the warming events.

The need to do more studies on the CEJ, in order to understand its features and the morphology of both the EEJ and the CEJ, along various longitudinal sectors has been emphasised by some authors such as Bolaji et al. (2014) and Chandrasekhar et al. (2014), among others. The main purpose of the present study is to investigate the longitudinal variability of the EEJ and the occurrence of its CEJ along the geomagnetic equatorial belt using well-spaced stations with sufficient data availability from the South American, African, and Philippine magnetic equatorial sectors. This study also compares the spatial and temporal morphology of EEJ and CEJ occurrence along various equatorial sectors. 
Table 1. Geomagnetic observatories and their corresponding coordinates.

\begin{tabular}{lcrr|rr}
\hline Geomagnetic observatories & Code & \multicolumn{2}{c|}{ Geomagnetic coordinates } & \multicolumn{2}{c}{ Geographic coordinates } \\
\cline { 3 - 6 } & & Longitude $\left(^{\circ}\right)$ & Latitude $\left(^{\circ}\right)$ & Longitude $\left({ }^{\circ} \mathrm{E}\right)$ & Latitude $\left({ }^{\circ} \mathrm{N}\right)$ \\
\hline Huancayo & HUA & 356.54 & -1.80 & -75.22 & -12.07 \\
Trelew & TRW & 354.38 & -33.05 & -65.30 & -43.25 \\
Ilorin & ILR & 76.80 & -1.82 & 4.68 & 8.50 \\
Lagos & LAG & 75.33 & -3.04 & 3.43 & 6.48 \\
Addis Ababa & ADD & 110.47 & 0.18 & 38.77 & 9.04 \\
Nairobi & NAB & 108.18 & -10.65 & 36.48 & -1.16 \\
Langkawi & LKW & 171.9 & -2.32 & 99.78 & 6.30 \\
Davao & DAV & 125.58 & -1.02 & 125.0 & 7.00 \\
Yap & YAP & 209.06 & 1.49 & 138.08 & 9.50 \\
Hualien & HLN & 193.05 & 16.86 & 138.12 & 9.53 \\
\hline
\end{tabular}

\section{Methods and analyses}

Obtained from ground-based magnetometer observatories of the Magnetic Data Acquisition System (MAGDAS) of the International Centre for Space Weather Science and Education, Kyushu University Japan, as well as the INTERMAGNET global network, were 1 year of data of the horizontal components $(H)$ of the geomagnetic field for the year 2009 (mean annual sunspot number $R_{z}=3.1$ ). These observatories are located along the South American, African, and Philippine longitudes within the magnetic equatorial zone. The details of the geographic and geomagnetic coordinates of the selected stations and their distributions are shown in Table 1.

The EEJ produces a strong enhancement in the $H$ component magnetic field, measured by magnetometers located within $\pm 3^{\circ}$ of the magnetic equator; therefore, measuring this perturbation in equatorial magnetometers could provide a direct measure of the EEJ (Onwumechili, 1997; Yizengaw et al., 2014). Ilorin, Addis Ababa, Huancayo, Davao, Yap, and Langkawi are located within the equatorial electrojet belt, which lies around $\pm 3^{\circ}$ latitude of the magnetic equator, while Lagos, Nairobi, Trelew, and Hualien are outside the electrojet belt.

Since EEJ can be accurately considered during quiet conditions, this research employed the data obtained on magnetically quiet days $(\mathrm{Ap} \leq 3)$. Table 2 present the dates of the quiet days engaged in this work with their corresponding Ap indices. The concept of local time was used throughout this analysis to ensure a measure of accuracy as the stations vary from one local time to another.

The $H$ components of geomagnetic field stations located within and outside of the EEJ region are compared and the difference of the $H$ component within and outside the EEJ, $\Delta H$, was calculated. This difference is the only part of the $H$ component field that is related to the EEJ current contribution (Anderson et al., 2004). Thus, hourly equatorial electrojet strength at any EEJ station (EEJs) is given by the difference between the $H$ field at that location and another sta- tion outside the EEJ zone (EEJo) but close in longitude to it. Therefore hourly EEJ at various EEJ stations are

$$
\left.\begin{array}{ll}
\text { EEJ at Huancayo: } & \mathrm{EEJ}_{t}(\mathrm{HUA})=H_{t}(\mathrm{HUA})-H_{t}(\mathrm{TRW}) \\
\text { EEJ at Ilorin: } & \mathrm{EEJ}_{t}(\mathrm{ILR})=H_{t}(\mathrm{ILR})-H_{t}(\mathrm{LAG}) \\
\text { EEJ at Addis Ababa: } & \mathrm{EEJ}_{t}(\mathrm{ADD})=H_{t}(\mathrm{ADD})-H_{t}(\mathrm{NAB}) \\
\text { EEJ at Langkawi: } & \mathrm{EEJ}_{t}(\mathrm{LKW})=H_{t}(\mathrm{LKW})-H_{t}(\mathrm{HLN}) \\
\text { EEJ at Davao: } & \mathrm{EEJ}_{t}(\mathrm{DAV})=H_{t}(\mathrm{DAV})-H_{t}(\mathrm{HLN}) \\
\text { EEJ at Yap: } & \mathrm{EEJ}_{t}(\mathrm{YAP})=H_{t}(\mathrm{YAP})-H_{t}(\mathrm{HLN})
\end{array}\right\} \text {, }
$$

where $H_{t}(\mathrm{HUA}), H_{t}(\mathrm{TRW}), H_{t}(\mathrm{ILR}), H_{t}(\mathrm{LAG}), H_{t}(\mathrm{ADD})$, $H_{t}(\mathrm{NAB}), H_{t}(\mathrm{LKW}), H_{t}(\mathrm{HLN}), H_{t}(\mathrm{DAV})$, and $H_{t}(\mathrm{YAP})$ are hourly values of horizontal geomagnetic field component at local time $t$ hours at Huancayo, Trelew, Ilorin, Lagos, Addis Ababa, Nairobi, Langkawi, Hualien, Davao, and Yap respectively; $\mathrm{EEJ}_{t}(\mathrm{HUA}), \mathrm{EEJ}_{t}(\mathrm{ILR}), \mathrm{EEJ}_{t}(\mathrm{ADD})$, $\mathrm{EEJ}_{t}(\mathrm{LKW}), \mathrm{EEJ}_{t}(\mathrm{DAV})$, and $\mathrm{EEJ}_{t}(\mathrm{YAP})$ are hourly EEJ strength at local time $t$ hours at Huancayo, Ilorin, Addis Ababa, Langkawi, Davao, and Yap respectively.

It is pertinent to mention that LAG station at $-3.04^{\circ}$ geomagnetic latitude is $1.22^{\circ}$ south of ILR, barely outside the EEJ strip and may still have some EEJ magnetic effects. However, we were constrained to stick to the choice of the LAG-ILR station pair as LAG is the farthest station we could get along the same longitude as ILR within the observational network that we engaged in this work. Therefore, our choice of the LAG-ILR station pair, may have consequences for the accuracy of our representation of the EEJ at ILR.

These hourly values were further corrected for non-cyclic variation following Price and Stone (1964) in a method well explained in Rabiu et al. $(2007,2011)$.

Furthermore, since the CEJ is the reversed EEJ current, Gouin (1962), CEJ in daytime at any time $t$ is estimated when EEJ at that particular time is negative, that is

$\mathrm{CEJ}^{t}=\left(\mathrm{EEJ}^{t}<0\right)$.

In addition to using simple computer code to detect occurrence of the CEJ, physical inspection of plots of daily hourly profiles of electrojet strength EEJ $(H)$ was also carried out for all the available days. Due to lack of data at some stations, monthly total number of days analysed vary from one 


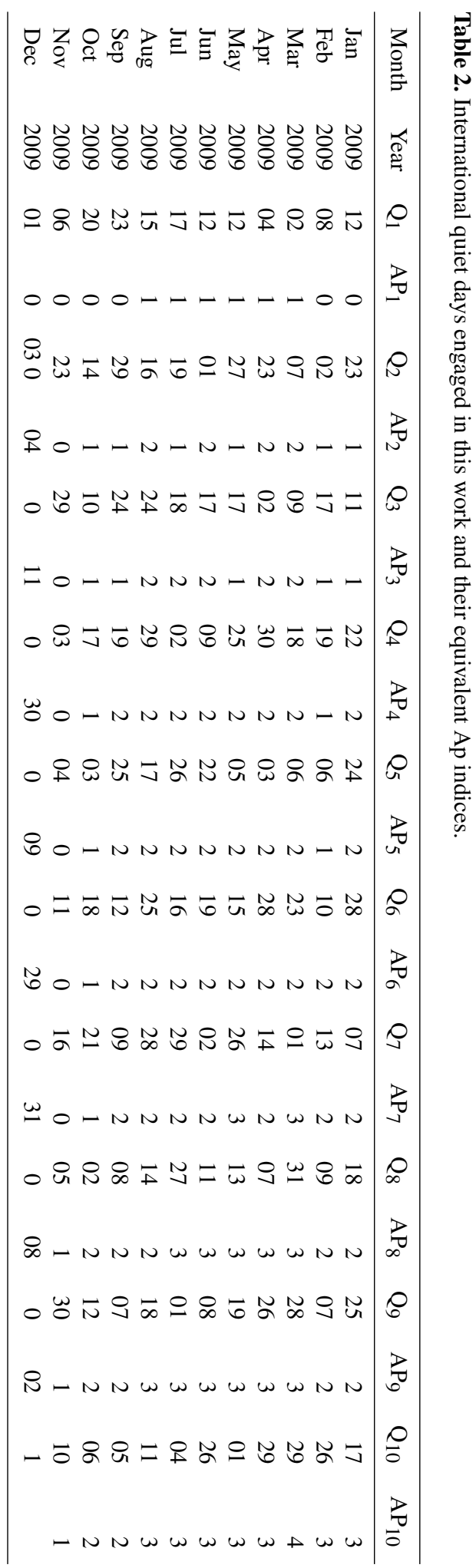

Table 3. Days of data availability (NA means "data not available").

\begin{tabular}{lrrrrrr}
\hline \multirow{2}{*}{ Month } & \multicolumn{6}{c}{ Number of days with data at different stations } \\
\cline { 2 - 7 } & HUA & ILR & ADD & LKW & DAV & YAP \\
\hline Jan & 10 & 3 & 8 & 10 & 10 & 10 \\
Feb & 10 & 8 & 10 & 10 & 10 & 8 \\
Mar & 10 & 8 & 10 & 9 & 5 & 9 \\
Apr & 10 & 6 & 10 & 9 & 10 & 9 \\
May & 10 & 6 & 10 & 10 & 10 & 9 \\
Jun & 10 & 7 & 8 & NA & 10 & 10 \\
Jul & 10 & 6 & 6 & 2 & 9 & 9 \\
Aug & 10 & 8 & 6 & NA & 10 & 10 \\
Sep & 10 & 9 & 9 & 10 & 10 & 5 \\
Oct & 10 & 10 & 8 & 6 & 10 & 7 \\
Nov & 10 & NA & 9 & NA & 10 & 10 \\
Dec & 10 & NA & 8 & NA & 10 & 10 \\
\hline Total & 120 & 71 & 102 & 66 & 114 & 106 \\
\hline
\end{tabular}

station to another. Table 3 shows the monthly total number of days on which data were available for all the stations.

Percentage occurrence of CEJ in a particular batch was estimated as

$\%$ occurrence of CEJ

$$
=\frac{\text { number of occurrence of CEJ }}{\text { Total number of days for which data were available }} \times 100
$$

Occurrence of morning CEJ (MCEJ) in \% was considered for the duration between 06:00 and 11:00 LT, while \% occurrence of afternoon CEJ (ACEJ) was considered for the duration between 13:00 and 18:00 LT.

\section{Results and discussion}

\subsection{EEJ characteristics at each station}

The variability of EEJ across the stations between 06:00 and 18:00 LT is presented in Fig. 1. The contour plot evidently shows the diurnal distribution of EEJ at each of the stations.

It is obvious from Fig. 1 that the EEJ undergoes variability from one longitudinal representative station to another. Figure 2 shows the variation of the maximum EEJ attained in any location with longitude. This puts the values at the stations as $192.5 \mathrm{nT}$ on 6 October 2009 at HUA $\left(-75.22^{\circ}\right)$, $40.7 \mathrm{nT}$ on 21 October 2009 at ILR $\left(4.68^{\circ}\right), 75.1 \mathrm{nT}$ on 11 December 2009 at $\operatorname{ADD}\left(38.77^{\circ}\right), 100.9 \mathrm{nT}$ on 19 September 2009 at LKW $\left(99.78^{\circ}\right), 144.2 \mathrm{nT}$ on 19 September 2009 at DAV $\left(125.0^{\circ}\right)$, and $103.6 \mathrm{nT}$ on 4 November 2009 at YAP $\left(138.08^{\circ}\right)$. These figures imply that we obtained the strongest EEJ of about 192.5 nT in the South American axis at Huancayo and a minimum peak of $40.7 \mathrm{nT}$ at Ilorin in western Africa. As noted earlier, the EEJ strength at Ilorin might be significantly underestimated due to the choice of the LAGILR station pair as the two stations are barely separated by 


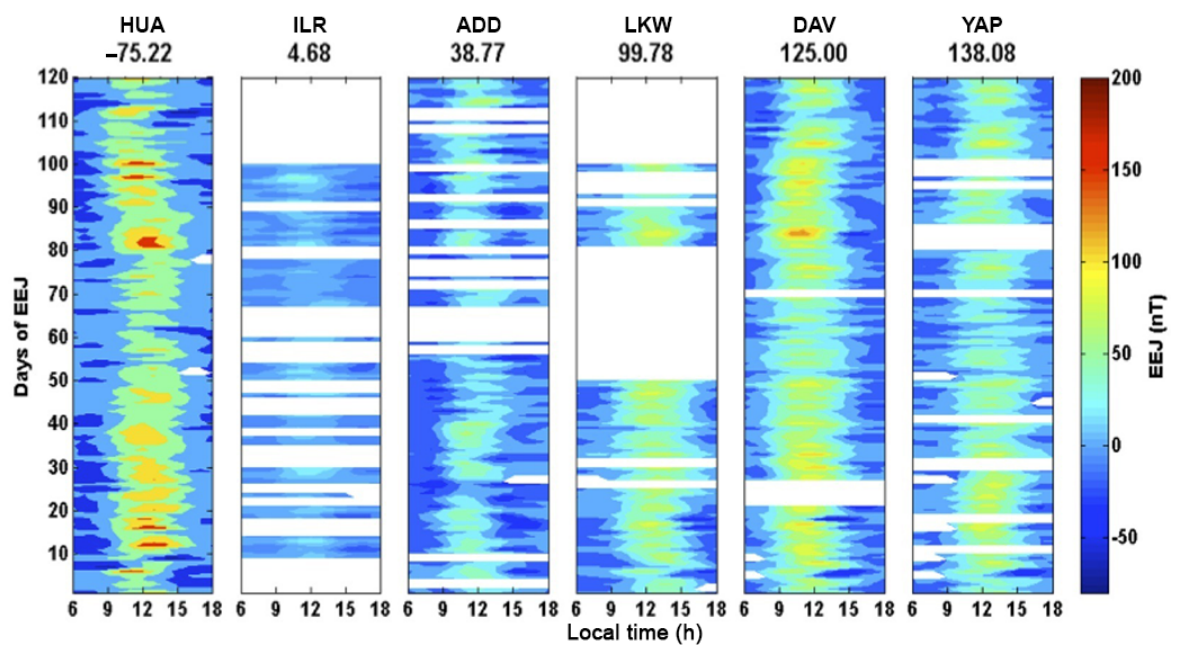

Figure 1. Variation of the equatorial electrojet (EEJ) among the stations.

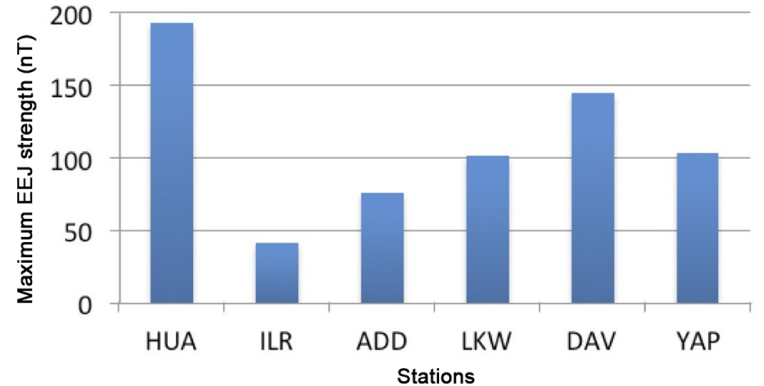

Figure 2. Variation of the maximum EEJ attained in any location with longitude.

$1.22^{\circ}$ and LAG is just at the edge of the EEJ strip. However, lack of adequate station pairs in this longitude sector makes the LAG-ILR choice unavoidable in the present analysis. It is hoped that this would be corrected in future work. Furthermore, Fig. 3 illustrates the variability of the amplitude of the maximum CEJ strength in the morning and afternoon from one station to another.

Longitudinal inequality of EEJ, which is well displayed in Figs. 1 and 2, underscores the effects of local winds in driving the EEJ according to Stening $(1985,1995)$. Doumouya et al. (1998, 2003), Jadhav et al. (2002), Rabiu et al. (2011), and Alken and Maus (2007), among others, had reported longitudinal variation of EEJ using different data sources and discussed the longitudinal inequality in terms of dynamics of migratory tides, propagating diurnal tide, and meridional winds. Jadhav et al. (2002) attributed the longitudinal inequality found in EEJ strength to non-migratory tides using Ørsted satellite magnetic field data. Luhr et al. (2004) engaged CHAMP satellite data and deduced that the longitude dependence of the EEJ intensity can be explained by varying cross-sectional area of the Cowling channel. Lühr et al. (2008) discussed the influence of non-migrating tides on

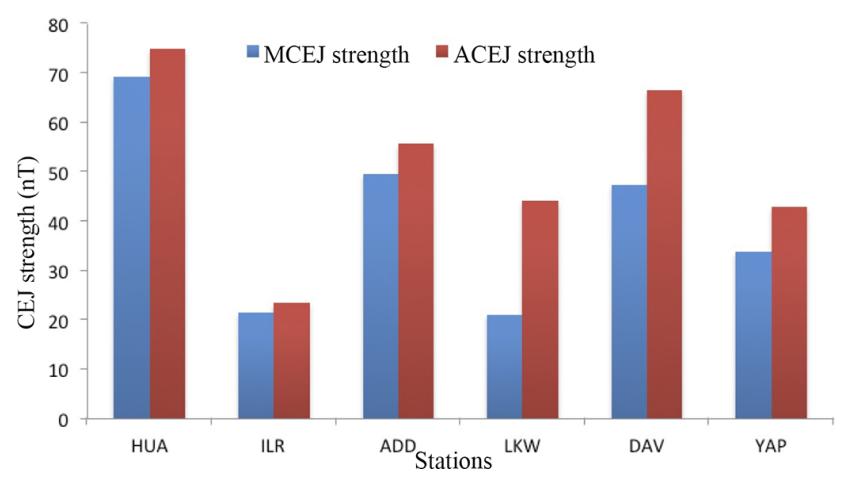

Figure 3. Variation of the maximum CEJ strength attained at any location with longitude.

the longitudinal variation of the EEJ by using the climatological model of EEJ derived earlier from Ørsted, CHAMP, and SAC-C satellite measurements by Alken and Maus (2007). Firstly Rabiu et al. (2011) and later Yizengaw et al. (2014) showed that EEJ strength is higher in eastern Africa than western Africa, with about $30^{\circ}$ longitudinal difference. The longitudinal inequality in the maximum strength of the CEJ either in the morning or afternoon across the stations, as displayed in Fig. 3, is a reflection of the longitudinal dependence of the EEJ. South American stations at Huancayo recorded the maximum CEJ strength just as it is known for its strong EEJ. The longitudinal variability in the strength of the EEJ obtained from our ground-based results here confirmed the reproducibility of the satellite-based results from other sources.

\subsection{Occurrence of CEJ}

Figures 4 and 5 presented the $\%$ occurrence of MCEJ and \% occurrence of afternoon CEJ in different months along dif- 


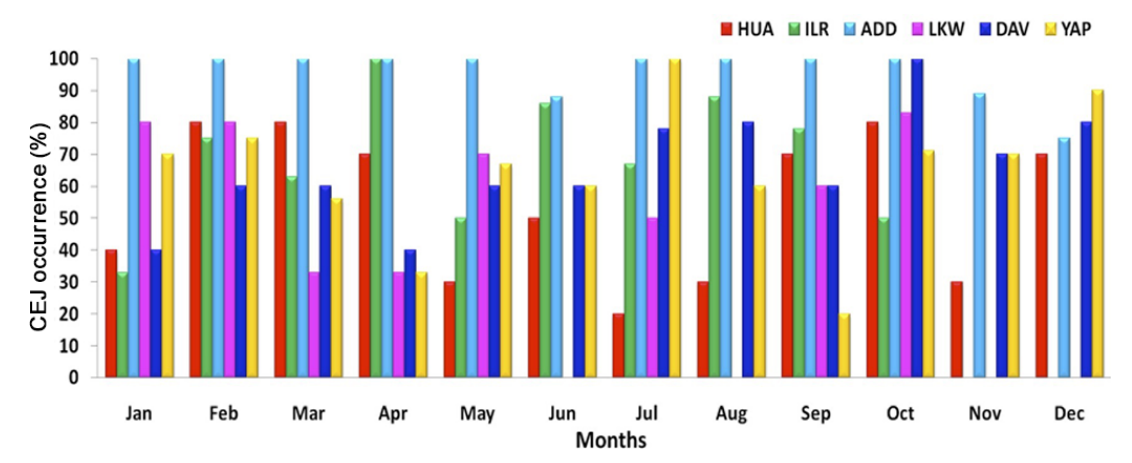

Figure 4. Percentage occurrence of morning CEJ.

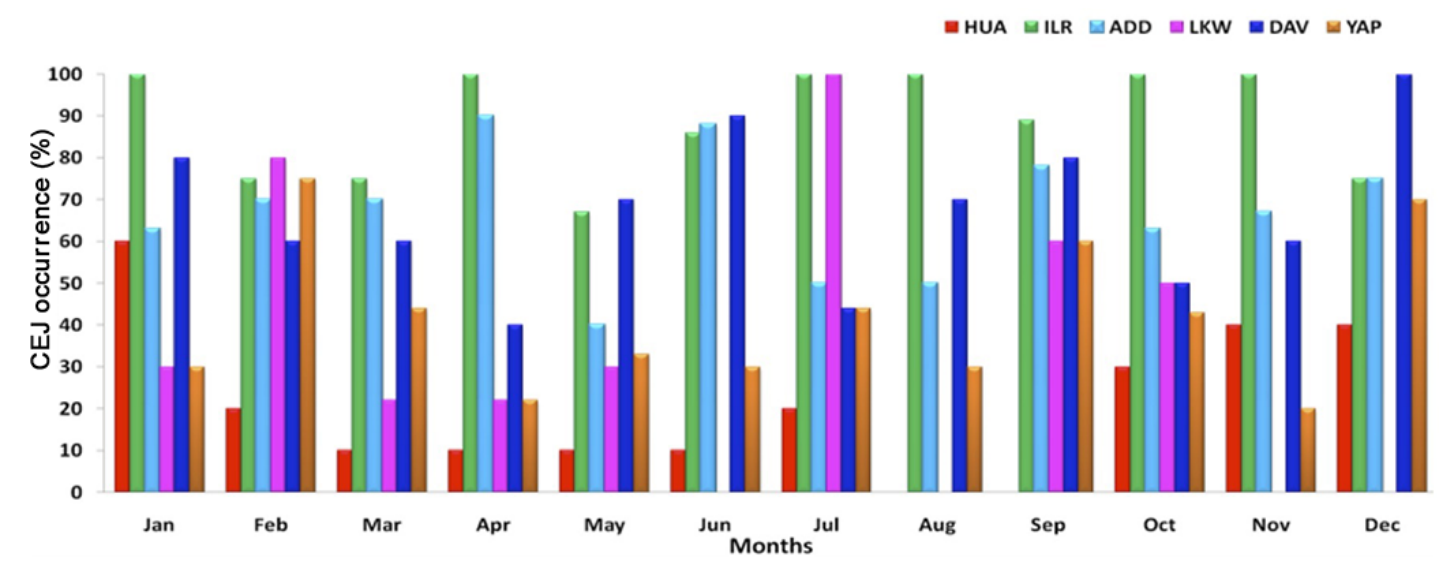

Figure 5. Percentage occurrence of afternoon CEJ.

ferent longitudes. Figure 6 shows the annual \% occurrence of MCEJ and ACEJ at all locations. Outstandingly clear in all the figures is the greater \% of occurrence of the CEJ at the African stations of ILR and ADD than elsewhere. The greatest \% occurrence of MCEJ was found at the eastern African station of $\mathrm{ADD}$, while the greatest \% occurrence of afternoon CEJ was found at the western African station of ILR. ADD recorded $100 \%$ of days with MCEJ for almost all the days of availability of data, except in the months of June, November, and December. Meanwhile, ILR in western Africa registered $100 \%$ occurrence of Afternoon CEJ in all the months of January, April, July, August, October and November. Figure 4 supported the fact that CEJ occurrence is more predominant in the African sector than other sectors considered in this work. In the overall analysis, the station with the strongest electrojet strength was found to have the least occurrence of the CEJ. It has often been reported by Onwumechili (1997), and some other authors, that the CEJ rarely occur during periods when the EEJ is strong. It may be right to assert that activities that support strong EEJ do inhibit occurrence of the CEJ.

The seasonal dependence of occurrence of the CEJ is presented in Figs. 7 and 8, where it is clear that percentage of occurrence of the CEJ varies with seasons across the stations.

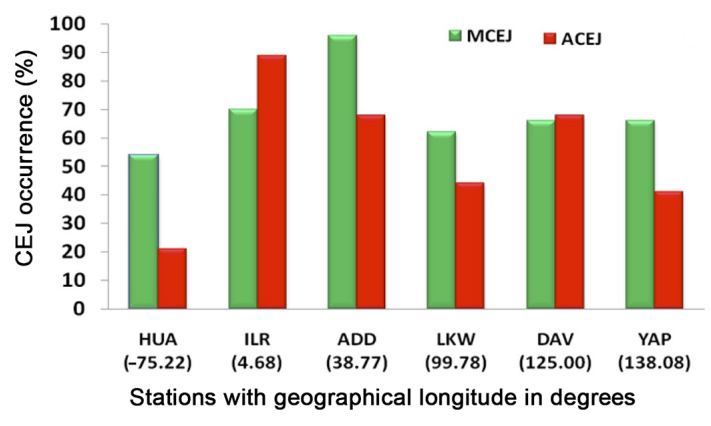

Figure 6. Yearly percentage of occurrence of the CEJ.

The order of seasonal variation of morning occurrence does not tally with the evening occurrence order at any station. For instance, there are equinoctial maxima at the two equinoxes when considering morning CEJ at Huancayo and Addis Ababa. These maxima have equal values at the two stations: $100 \%$ at Addis and $75 \%$ at Huancayo. No other stations had these double equinoctial maxima. However, Ilorin has March equinoctial maxima and recorded minimum morning occurrence of the CEJ at the September equinox. LKW, DAV, and YAP all recorded minimum morning occurrence at the March 


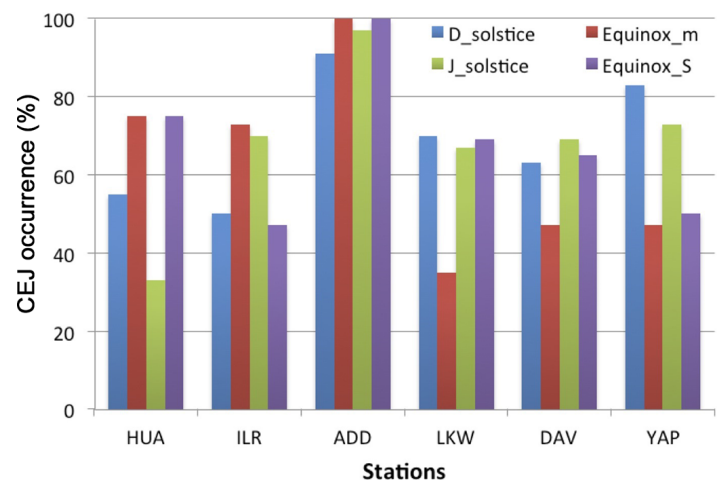

Figure 7. Seasonal variation of morning CEJ, MCEJ (D_solstice means December solstice, Equinox_m means March equinox, J_solstice means June solstice, Equinox_S means September equinox)

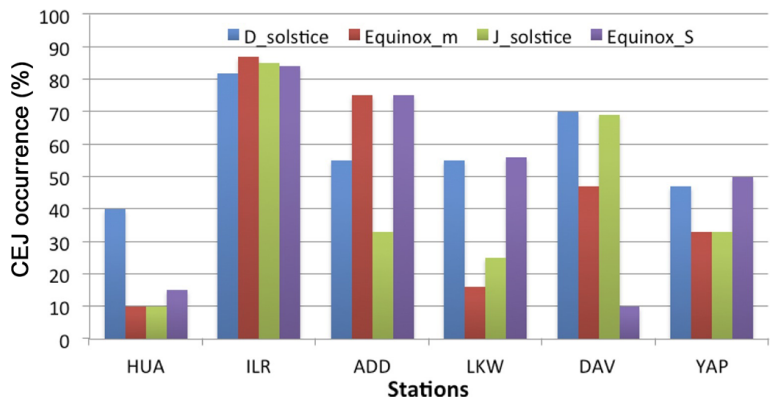

Figure 8. Seasonal variation of afternoon CEJ, ACEJ (D_solstice means December solstice, Equinox_m means March equinox, J_solstice means June solstice, Equinox_S means September equinox).

equinox. Minimum morning occurrence occurred at the December and June solstices at Addis Ababa and Huancayo.

Considering evening occurrence of the CEJ as shown in Fig. 8, only Addis Ababa recorded equal equinoctial maxima at the two equinoxes. Langkawi and Yap have maximum evening occurrences at the September equinox, followed by the December solstice. Ilorin recorded a March equinoctial maximum, while Huancayo and Davao have December solstitial maxima. Minimum evening occurrence was found in Davao in September equinox.

Figures 9 and 10 display the seasonal variation of the strength of the morning and ACEJ respectively across the stations. It is obvious that the seasonal variation of the occurrence of the CEJ really has no direct correlation with the seasonal variation of its strength. Seasonal variability exists in the strength of the CEJ at the two dispensations and any station and does not have uniform order of seasonal dependence, unlike EEJ, as reported in various literatures such as Onwumechili (1997) and the references therein.

Rabiu et al. (2017) noted that the seasonal distribution of the occurrences of the CEJ at different time regimes implies a seasonal variability of anyone or a combination of

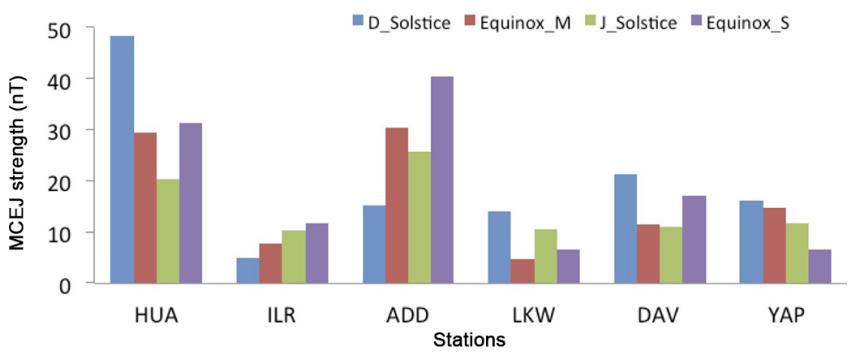

Figure 9. Seasonal variation of the strength of the morning CEJ across the stations. D_solstice means December solstice, Equinox_m means March equinox, J_solstice means June solstice, and Equinox_S means September equinox.

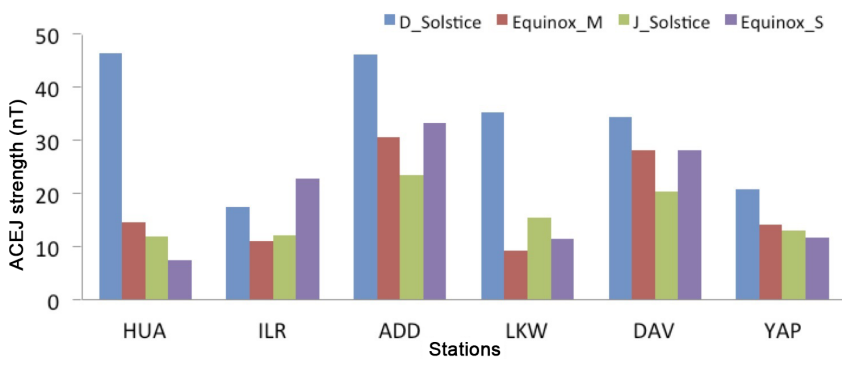

Figure 10. Seasonal variation of the strength of the afternoon CEJ across the stations. D_solstice means December solstice, Equinox_m means March equinox, J_solstice means June solstice, and Equinox_S means September equinox.

the following mechanisms responsible for the occurrence of the CEJ itself: height-varying local winds capable of causing the reversal in the current system (Richmond, 1973), gravity wave-associated vertical winds (Raghavarao and Anandarao, 1980), global-scale tidal winds with appropriate phase combination (Forbes and Lindzen, 1976; Marriott et al., 1979; Forbes, 1981; Singh and Cole, 1987; Stening, 1989; Somayajulu et al., 1993), high-latitude stratospheric warming events (Stening et al., 1996; Vineeth et al., 2009), daytime vertically driven downward electric field (negative $E_{z}$ ) (Onwumechili, 1997), and semidiurnal tide (Gurubaran, 2002; Sridharan et al., 2002, 2009).

The variances in order of seasonal variation of percentages of occurrence of the CEJ at different longitudes could be related to local effects such as seasonal variability of local and neutral winds. In addition, Chandrasekhar et al. (2014) in their study of occurrence of the CEJ at two new remote electrojet sites in India separated by $15^{\circ}$ longitude presented evidence of the CEJ being caused by local perturbations in their results. They considered the following as possible factors of CEJ occurrence not being simultaneously universal: nonmigrating eastward- and westward-propagating diurnal tides and local meteorological phenomena associated with upper mesospheric temperature, wind, and density variations.

Rabiu et al. (2017) found a situation where $41.3 \%$ of the afternoon CEJ in western Africa has counterpart occurrence 
in the morning on the same day in eastern Africa instead of in the afternoon, a scenario they described as Asymmetry2; they attributed this longitudinal variability in the local time of occurrence of the CEJ along these longitudes to the differences in meridional currents across different longitudes. Chandrasekhar et al. (2014) found non-simultaneous occurrence of the CEJ between two Indian stations separated by $15^{\circ}$ longitude and thus threatened the CEJ longitudinal extent of $30^{\circ}$ earlier reported by Kane (1973), Kane and Trivedi (1980), and Rastogi (1974). Rastogi and Yumoto (2006) reported that the direction of meridional current varies significantly with longitude and, possibly, with the local time and season. Rabiu et al. (2017) ascribed the variation in percentage of occurrence of the CEJ with months to the longitudinal variability of thermospheric winds that drive the ionospheric dynamo even on magnetic quiet days, as mentioned by Vichare and Richmond (2005), which could be due to atmospheric solar tides that are not sun synchronous (Hagan and Forbes, 2002, 2003). Other factors that have been reported to be responsible for variation in percentage of occurrence of the CEJ along different longitudes include eastward zonal winds (Ramkumar et al., 2002); gravity wave-tidal interactions and vertical coupling process in the mesosphere lower thermosphere - ionosphere (MLTI), resulting in neutral winds (Vineeth et al., 2007; Liu and Watanabe, 2008) via DE3 tidal modulation of the $\mathrm{E}$ layer dynamo, changes in temperature, wind and density variation in the upper mesospheric region due to the influence of tides, gravity, and planetary waves from the stratosphere and troposphere (Vineeth et al., 2012), which strongly influence ionospheric conductivity over short spatial scales of approximately $1600 \mathrm{~km}$; differences in local wind shears that modify jet fields (especially during the noon hours) (Reddy and Devasia, 1981); and changes in neutral winds (Sridharan et al., 2002; Vineeth et al., 2007).

\section{Conclusions}

This work investigated the longitudinal variability of the equatorial electrojet (EEJ) and the occurrence of its counter equatorial electrojet (CEJ) along the geomagnetic equatorial belt and made use of data from the following electrojet stations whose longitudes are given in parentheses: Huancayo HUA $\left(-75.22^{\circ}\right)$, Ilorin ILR $\left(4.68^{\circ}\right)$, Addis Ababa ADD $\left(38.77^{\circ}\right)$, Langkawi LKW $\left(99.78^{\circ}\right)$, Davao DAV (125.0 $)$, and Yap YAP $\left(138.08^{\circ}\right)$. The study compared the spatial and temporal morphology of EEJ and CEJ occurrence along various equatorial sectors.

Our results indicated that the EEJ undergoes variability from one longitudinal representative station to another, with the strongest EEJ of about $192.5 \mathrm{nT}$ in the South American axis at Huancayo and a minimum peak of $40.7 \mathrm{nT}$ at Ilorin in western Africa. Obtained longitudinal inequality in the EEJ was explicable in terms of the effects of local winds
(Stening, 1985, 1995), dynamics of migratory tides, propagating diurnal tide, and meridional winds (Doumouya et al., 1998, 2003; Jadhav et al., 2002; Rabiu et al., 2011; Alken and Maus, 2007).

Of all the sectors considered, the African stations of ILR and ADD registered the greatest \% of occurrence of the CEJ than elsewhere. The greatest \% occurrence of MCEJ was found at Addis Ababa (eastern Africa), while the greatest $\%$ occurrence of afternoon CEJ was found at Ilorin (western Africa). Thus, CEJ occurrence is more predominant in the African sector than other sectors considered in this work. Huancayo in South America, with the strongest electrojet strength, was found to have the least occurrence of the CEJ. It may be right to assert that activities that support strong EEJ do inhibit the occurrence of the CEJ.

We reported a variation of percentage of occurrence of the CEJ with seasons across the longitudes. The order of seasonal variation of morning occurrence does not tally with the evening occurrence order at any station. Semi-annual equinoctial maxima in percentage of morning occurrence of the CEJ were obtained at Huancayo and Addis Ababa. No other stations had these double equinoctial maxima. However, Ilorin has March equinoctial maxima and recorded minimum morning occurrence of the CEJ at the September equinox. LKW, DAV, and YAP all recorded minimum morning occurrence at the March equinox. Minimum morning occurrence occurred at the December and June solstices at Addis Ababa and Huancayo respectively. Only Addis Ababa recorded equal equinoctial maxima in percentage of evening occurrence of the CEJ. The seasonal distribution of the occurrences of the CEJ at different time regimes implies a seasonal variability of causative mechanisms responsible for occurrence of the CEJ.

Data availability. The data collected at Huancayo, Trelew, and Addis Ababa can be obtained from www.intermagnet.org. While those of Lagos, Ilorin, Nairobi, Langkawi, Davao, Yap, and Hualien are obtainable at http://magdas.serc.kyushu-u.ac.jp/.

Competing interests. The authors declare that they have no conflict of interest.

Acknowledgements. The results presented in this paper rely on the data collected at Huancayo, Trelew, and Addis Ababa. We thank the host institutes for supporting their operation and INTERMAGNET for promoting high standards of magnetic observatory practice (www.intermagnet.org). The Magnetic Data Acquisition System (MAGDAS) data used for this paper were obtained from the International Center for Space Weather Science and Education (ICSWSE), Kyushu University, Fukuoka, Japan. MAGDAS was supported by the Japan Society for the Promotion of Science (JSPS) JSPS KAKENHI grant no. 268022. All the hosts and management of the MAGDAS facilities at the stations whose 
data were engaged in this research are also acknowledged. Nurul Shazana Abdul Hamid was supported by grants GGPM-2015020 and FRGS/1/2015/ST02/UKM/02/1. Akimasa Yoshikawa was supported in part by the JSPS Core-to-Core Program (B. AsiaAfrica Science Platforms), Formation of Preliminary Center for Capacity Building for Space Weather Research and JSPS KAKENHI grants $15 \mathrm{H} 05815$. The authors remain grateful to the anonymous reviewers for the positive criticism.

The topical editor, J. Makela, thanks the two anonymous referees for help in evaluating this paper.

\section{References}

Alex, S. and Mukherjee, S.: Local time dependence of the equatorial counter electrojet effect in a narrow longitudinal belt, Earth Planets Space, 53, 1151-1161, doi:10.1186/BF03352410, 2001.

Alken, P. and Maus, S.: Spatio-temporal characterization of the equatorial electrojet from CHAMP, Ørsted, and SAC-C satellite magnetic measurements, J. Geophys. Res., 112, A09305, doi:10.1029/2007JA012524, 2007.

Amory-Mazaudier, C., Vila, P., Achache, J., Achy-Seka, A., Albouy, Y., Blanc, E., Boka, K., Bouvet, J., Cohen, Y., Dukhan, M., Doumouya, V., Fambitakoye, O., Gendrin, R., Goutelard, C., Hamoudi, M., Hanbaba, R., Hougninou, E., Huc, E. C., Kakou, K., Kobea-Toka, A., Lassudrie-Duchesne, P., Mbipom, E., Menvielle, M., Ogunade, S. O., Onwumechili, C. A., Oyinloye, J. O., Rees, D., Richmond, A., Sambou, E., Schmuker, E., Tirefort, J. L., and Vassal, J.: International equatorial electrojet year: the African sector, Revista Brasileira de Geofisica, 11, 303-317, 1993.

Anderson, D., Anghel, A., Chau, J. L., and Veliz, O.: Daytime vertical $\boldsymbol{E} \times \boldsymbol{B}$ drift velocities inferred from ground-based magnetometer observations at low latitudes, Space Weather, 2, S11001, doi:10.1029/2004SW000095, 2004.

Balan, N., Chen, C. Y., Liu, J. Y., and Bailey, G. J.: Behaviour of the low-latitude ionosphere-plasmasphere system at long deep solar minimum, Indian J. Radio Space, 41, 89-97, 2012.

Bolaji, O. S., Oyeyemi, E. O., Fagundes, P. R., deAbreu, A. J., deJesus, R., Rabiu, A. B., and Yoshikawa, A.: Counter Electrojet Events using Ilorin Observations during a Low Solar Activity Period, The African Review of Physics, 9, 361-376, 2014.

Chandrasekhar, N. P., Arora, K., and Nagarajan, N.: Evidence of short spatial variability of the equatorial electrojet at close longitudinal separation, Earth Planets Space, 66, 110, doi:10.1186/1880-5981-66-110, 2014.

Chapman, S.: The equatorial electrojet as detected from the abnormal electric current distribution above Huancayo, Peru and elsewhere, Arch. Meteor. Geophy. B., 4, 368-390, 1951.

Chau, J. L., Fejer, B. G., and Goncharenko, L. P.: Quiet variability of equatorial $\boldsymbol{E} \times \boldsymbol{B}$ drifts during a sudden stratospheric warming event, Geophys. Res. Lett., 36, 1-4, 2009.

Doumouya, V. and Cohen, Y.: Improving and testing the empirical equatorial electrojet model with CHAMP satellite data, Ann. Geophys., 22, 3323-3333, doi:10.5194/angeo-22-33232004, 2004.
Doumouya, V., Vassal, J., Cohen, Y., Fambitakoye, O., and Menvielle, M.: Equatorial electrojet at African longitudes: first results from magnetic measurements, Ann. Geophys., 16, 658666, doi:10.1007/s00585-998-0658-9, 1998.

Doumouya, V., Cohen, Y., Arora, B. R., and Yumoto, K.: Local time and longitude dependence of the equatorial electro-jet magnetic effects, J. Atmos. Sol.-Terr. Phy., 65, 1265-1282, 2003.

Fambitakoye, O. and Mayaud, P. N.: Equatorial electrojet and regular daily variation SR - I. A determination of the equatorial electrojet parameters, J. Atmos. Terr. Phys., 38, 1-17, 1976a.

Fambitakoye, O. and Mayaud, P. N.: Equatorial electrojet and regular daily variation SR - II. The center of the equatorial electrojet, J. Atmos. Terr. Phys., 38, 19-26, 1976 b.

Forbes, J. M.: The equatorial electrojet, Rev. Geophys. Space Phys., 19, 469-504, 1981.

Forbes, J. M. and Lindzen, R. S.: Atmospheric solar tides and their electrodynamic effects - II. The equatorial electrojet, J. Atmos. Terr. Phys., 38, 911-920, 1976.

Gouin, P.: Reversal of the Magnetic Daily Variations at Addis Ababa, Nature, 139, 1145-1146, 1962.

Gouin, P. and Mayaud, P. N.: A propos de l'existence possible d'un "Contre Electrojet" aux latitudes, magnetiques equatoriales, Ann. Geophys., 23, 41-47, 1967.

Gurubaran, S.: The equatorial counter electrojet: Part of a worldwide current system?, Geophys. Res. Lett., 29, 1337, doi:10.1029/2001GL014519, 2002.

Hagan, M. E. and Forbes, J. M.: Migrating and non-migrating diurnal tides in the middle and upper atmosphere excited by tropospheric latent heat release, J. Geophys. Res., 107, 475, doi:10.1029/2001JD001236, 2002.

Hagan, M. E. and Forbes, J. M.: Migrating and non-migrating semi-diurnal tides in the upper atmosphere excited by tropospheric latent heat release, J. Geophys. Res., 108, 1062, doi:10.1029/2002JA009466, 2003.

Hanuise, C., Mazaudier, C., Vila, P., Blanc, M., and Crochet, M.: Global dynamo simulation of ionospheric currents and their connection with the equatorial electrojet and counter electrojet: A case study, J. Geophys. Res., 88, 253-270, 1983.

Jadhav, G., Rajaram, M., and Rajaram, R.: A detailed study of equatorial electrojet phenomenon using oersted satellite observations, J. Geophys. Res., 107, 1175, doi:10.1029/2001JA000183, 2002.

Kane, R. P.: Comparison of geomagnetic changes in India and the POGO data, J Atmos. Terr. Phys., 35, 1249-1252, doi:10.1016/0021-9169(73)90022-6, 1973.

Kane, R. P.: Geomagnetic field variations, Space Sci. Rev., 18, 413540, 1976.

Kane, R. P. and Trivedi, N. B.: Implication of $Z$ variations during a near noon equatorial counter electrojet on March 6, 1967 in the Indian sector, J. Geophys. Res., 85, 4705-4710, 1980.

Liu, H. and Watanabe, S.: Seasonal variation of the longitudinal structure of the equatorial ionosphere: does it reflect tidal influences from below?, J. Geophys. Res., 113, A08315, doi:10.1029/2008JA013027, 2008.

Luhr, H., Maus, S., and Rother, M.: Noon-time equatorial electrojet: Its spatial features as determined by the CHAMP satellite, J. Geophys. Res., 109, A01306, doi:10.1029/2002JA009656, 2004.

Lühr, H., Rother, M., Häusler, K., Alken, P., and Maus, S.: The influence of non-migrating tides on the longitudinal variation 
of the equatorial electrojet, Geophys. Res. Lett., 113, A08313, doi:10.1029/2008JA013064, 2008.

Marriott, R. T., Richmond, A. D., and Venkateswaran, S. V.: The quiet time equatorial electrojet and counter-electrojet, J. Geomagn. Geoelectr., 31, 311-340, 1979.

Mayaud, P. N.: The Equatorial Counter Electrojet: A review of its geomagnetic aspects, J. Atmos. Sol.-Terr. Phy., 39, 1055-1070, 1977.

Mazaudier, C. A., Kobea, A., Vila, P., Achy-Séka, A., Blanc, E., Boka, K., Bouvet, J., Cécile, J.-F., Cohen, Y., Curto, J.J., Dukhan, M., Doumouya, V., Fambitakoye, O., Farges, T., Goutelard, C., Guisso, E., Hanbaba, R., Houngninou, E., Kone, E., Lassudrie-Duchesne, P., Lathuillere, C., Leroux, Y., Menvielle, M., Obrou, E., Petitdidier, M., Ogunade, S. O., Onwumechili, C. A., Rees, D., Sambou, E., Sow, M., and Vassal, J.: On equatorial geophysics studies: a review on the IGRGEA results during the last decade, J. Atmos. Terr. Phys., 67, 301-313, doi:10.1016/j.jastp.2004.10.001, 2005.

Onwumechili, C. A.: The Equatorial Electrojet. Gordon and Breach Science Publishers, the Netherlands, 627 pp., 1997.

Onwumechili, C. A. and Akasofu, S. I.: On the abnormal depression of $S_{q}(\mathrm{H})$ under the equatorial electrojet in the afternoon, J. Geomagn. Geoelectr., 24,161-173, 1972.

Patil, A. R., Rao, D. R. K., and Rastogi, R. G.: Equatorial electrojet strength in the Indian and American sectors, Part I, during low solar activity, J. Geomagn. Geoelectr., 42, 801-811, 1990a.

Patil, A. R., Rao, D. R. K., and Rastogi, R. G.: Equatorial electrojet strength in the Indian and American sectors, Part II, during high solar activity, J. Geomagn. Geoelectr., 42, 813-823, 1990b.

Price, A. T. and Stone, D. J.: The quiet day magnetic variation during the IGY, Annals of the International Geophysical Year, IGY, 35, Part III, 64, Pergamon, Oxford, UK, 65-269, 1964.

Rabiu, A. B., Mamukuyomi, A. I., and Joshua, E. O.: Variability of equatorial ionosphere inferred from geomagnetic field measurements, B. Astron. Soc. India, 35, 607-618, 2007.

Rabiu, A. B., Yumoto, K., Falayi, E. O., Bello, O. R., and MAGDAS/CPMN Group: Ionosphere over Africa: Results from geomagnetic field measurement during international Heliophysical Year IHY, Journal of Sun and Geosphere, 6, 61-64, 2011.

Rabiu, A. B., Onwumechili, C. A., Nagarajan, N., and Yumoto, K.: Characteristics of equatorial electrojet over India determined from a thick current shell model, J. Atmos. Sol.-Terr. Phy., 92, 105-115, doi:10.1016/j.jastp.2012.10.014, 2013.

Rabiu, A. B., Folarin, O. O., Uozumi, T., and Yoshikawa, A.: Simultaneity and asymmetry in the occurrence of counterequatorial electrojet along African longitudes, in: Ionospheric Space Weather: Longitude and Hemispheric Dependences and Lower Atmosphere Forcing, Geophysical Monograph 220, 1st Edn., edited by: Fuller-Rowell, T., Yizengaw, E., Doherty, P. H., and Basu, S., American Geophysical Union, John Wiley \& Sons, Inc., 21-31, 2017.

Raghavarao, R. and Anandarao, B. G.: Vertical winds as a plausible cause for equatorial counter electrojet, Geophys. Res. Lett., 7, 357-360, 1980.

Ramkumar, T. K., Gurubaran, S., and Rajaram, R.: Lower E-region MF radar spaced antenna measurements over magnetic equator, J. Atmos. Sol.-Terr. Phy., 64, 1445-1453, 2002.
Rangarajan, G. K. and Rastogi, R. G.: Longitudinal difference in magnetic field variations associated with quiet day counter electrojet, J. Geomagn. Geoelectr., 45, 649-656, 1993.

Rastogi, R. G.: Longitudinal variation in the equatorial electrojet, J. Atmos. Terr. Phys., 24, 1031-1040, 1962.

Rastogi, R. G.: Westward equatorial electrojet during daytime hours, J. Geophys. Res., 79, 1503-1512, doi:10.1029/JA079i010p01503, 1974.

Rastogi, R. G.: The equatorial electrojet: magnetic and ionospheric effects, Geomagnetism, edited by: Jacobs, J. A., Academic Press, London, Vol. 3, chap. 7, 461-525, 1989.

Rastogi, R. G. and Yumoto, K.: Equatorial electrojet in the East Brazil anomaly region, Earth Planets Space, 58, 103-106, 2006.

Reddy, C. A.: The equatorial electrojet: a review of the ionospheric and geomagnetic aspects, J. Atmos. Terr. Phys., 43, 557-571, doi:10.1016/0021-9169(81)90118-5, 1981.

Reddy, C. A.: The equatorial electrojet, Pure Appl. Geophys., 131, 485-508, 1989.

Reddy, C. A. and Devasia, C. V.: Height and latitude structure of electric fields and currents due to local east-west winds in the equatorial electrojet, J. Geophys. Res., 86, 5751-5767, 1981.

Richmond, A. D.: Equatorial Electrojet-I, Development of a Model including Wind and Instabilities, J. Atmos. Terr. Phys., 35, 10831103, 1973.

Singh, A. and Cole, K. D.: A numerical model of the ionospheric dynamo - III, Electric current at equatorial and low latitudes, J. Atmos. Terr. Phys., 49, 539-547, 1987.

Somayajulu, V. V., Cherian, L., Rajeev, K., Ramkumar, G., and Raghava Reddy, C.: Mean winds and tidal components during counter electrojet events, Geophys. Res. Lett., 20, 1443-1446, 1993.

Sridharan, S., Gurubaran, S., and Rajaram, R.: Structural changes in the tidal components in the mesospheric winds as observed by the MF radar during afternoon counter electrojet events, J Atmos. Sol.-Terr. Phys., 64, 1455-1463, doi:10.1016/S13646826(02)00109-8, 2002.

Sridharan, S., Sathishkumar, S., and Gurubaran, S.: Variabilities of mesospheric tides and equatorial electrojet strength during major stratospheric warming events, Ann. Geophys., 27, 4125-4130, doi:10.5194/angeo-27-4125-2009, 2009.

Stening, R. J.: Modeling the equatorial electrojet, J. Geophys. Res., 90, 1705-1719, doi:10.1029/JA090iA02p01705, 1985.

Stening, R. J.: A calculation of ionospheric currents due to semidiurnal asymmetric tides, J. Geophys. Res., 94, 1525-1531, 1989.

Stening, R. J.: What drives the equatorial electrojet?, J. Atmos. Terr. Phys., 57, 1117-1128, 1995.

Stening, R. J., Meek, C. E., and Manson, A. H.: Upper atmosphere wind systems during reverse equatorial electrojet events, Geophys. Res. Lett., 23, 3243-3246, 1996.

Vichare, G. and Richmond, A. D.: Simulation study of the longitudinal variation of evening vertical ionospheric drifts at the magnetic equator during equinox, J. Geophys. Res., 110, A05304, doi:10.1029/2004JA010720, 2005.

Vineeth, C., Pant, T. K., Devasia, C. V., and Sridharan, R.: Highly localized cooling in daytime mesopause temperature over the dip equator during counter electrojet events: first results, Geophys. Res. Lett., 34, L14101, doi:10.1029/2007GL030298, 2007.

Vineeth, C., Kumar Pant, T., and Sridharan, R.: Equatorial counter electrojets and polar stratospheric sudden warmings - a classical 
example of high latitude-low latitude coupling?, Ann. Geophys., 27, 3147-3153, doi:10.5194/angeo-27-3147-2009, 2009.

Vineeth, C., Pant, T. K., and Hossain, M. M.: Enhanced gravity wave activity over the equatorial MLT region during counter electrojet events, Indian J. Radio Space, 41, 258-263, 2012.
Yizengaw, E., Moldwin, M. B., Zesta, E., Biouele, C. M., Damtie, B., Mebrahtu, A., Rabiu, B., Valladares, C. F., and Stoneback, R.: The longitudinal variability of equatorial electrojet and vertical drift velocity in the African and American sectors, Ann. Geophys., 32, 231-238, doi:10.5194/angeo-32-231-2014, 2014. 